\title{
DE FORTUINLIJKE LOOPBAAN IN SURINAME VAN DEN ZWEED C. G. DAHLBERG \\ DOOR
}

FRED. OUDSCHANS DENTZ

Het aantal vreemdelingen in dienst van de West-Indische Compagnie is - evenals bij de O.I.C. - vrij groot geweest. Velen hebben belangrijke plaatsen in Oost en West ingenomen en wetenschappelijk werk verricht. Ook zijn tal van vreemdelingen als militairen naar onze koloniën vertrokken en vooral was dit met Suriname het geval, waar de strijd tegen de Marrons (weggeloopen negerslaven) in het midden der 18de eeuw een vrij groote legermacht vereischte.

Reeds onder gouverneur Van Aerssen van Sommelsdyck hadden zich tal van vreemdelingen als planters in Suriname gevestigd en hun aantal nam voortdurend toe. Van hen kwamen er verscheidenen tot grooten welstand en werden plantage-eigenaren.

Zoo zien wij Franschen, Zwitsers, Duitschers, Zweden, Schotten, zelfs Italianen in Suriname wonen. $\mathrm{Zij}$, die plantagebezitters werden, namen al spoedig een invloedrijke positie in de samenleving in, en werden geleidelijk als medebestuurders van 's lands zaken geroepen, waartoe volgens art. 19 van het octrooi de ,,aanzienlijkste, verstandigste en moderaatste" ingezetenen als raadsleden - hoewel onbezoldigd - waren uitverkoren. Van die vreemdelingen waren er zelfs verscheidenen - zoowel burgers als militairen - die de Nederlandsche taal niet eens konden schrijven. Een opmerkelijk verschijnsel was het voorts, dat velen der vreemdelingen met Nederlandsche vrouwen huwden, en aangezien de sterfte onder de mannen in die dagen groot was, zag men niet zelden, dat de vrouwen twee- drie- en meermalen in het huwelijk traden, waardoor in de kleine samenleving een onderling verwante côterie ontstond, welke grooten invloed op den gang van zaken uitoefende. 
Onder de vreemdelingen, die als militair in het midden der 18de eeuw in dienst der W.I. Compagnie naar Suriname kwamen, zien wij een Zweed, Carl Gustaf Dahlberg, in Nieuw Copia (waarschijnlijk is bedoeld Nyköping) geboren. Hij behoorde tot de Luthersche (Augsburgsche) confessie. De directeuren der W.I.C. hadden Dahlberg aan den gouverneur aanbevolen. De jonge man is arm in Suriname aangekomen, slechts in het bezit van enkele stuivers, en is er als rijk man overleden.

Hij bracht het tot sous-lieutenant op 3 Mei 1748 en werd op 1 Maart 1752 op herhaald verzoek uit den militairen dienst ontslagen.

Dahlberg was een man, die een gemakkelijk leven verkoos boven een van ontbering en zwaren militairen dienst. Het land beviel hem goed, en om zijn positie te verbeteren en zich verder op te werken zag hij uit naar een Nederlandsche levensgezellin, die hem in het maatschappelijk leven hooger kon opvoeren. Zijn oog viel op Johanna Catharina Bedloo, weduwe van den burgerkapitein E. Brouwer, een op 13 Januari 1721 geboren dochter van Willem Bedloo, een der oudste en meest bekende kolonisten, eigenaar van de plantage "Nieuw Timotibo”, welke bekendheid verworven heeft door den negerslaaf Quassie, een vriend der blanken. Deze is de man, die het naar hem genoemde koortswerend middel uit een zekere struik, het kwassiehout, heeft gevonden.

Everardus Brouwer, raad van Civiele Justitie, een groot tegenstander van den gouverneur, was in 1747 uit de kolonie gezet, evenals de burger-kapitein Jan Pieterse Visser en de Israëlietische burger-kapitein Isaac Carilho, op grond van het aan den gouverneur en de raden toegekende recht van politieke uitzetting, aangezien zij door hun woelig gedrag en tegenwerking de rust in de kolonie verstoorden. Het schip, waarop Visser vertrokken was, kwam nimmer aan, en de boot, waarmede Brouwer de kolonie verliet, werd door Fransche kapers genomen. Hij overleed te Morlaix, een plaats, waar het kaperschip was binnengeloopen.

Door zijn verloving nu met de weduwe Brouwer werd Dahlberg, die tevoren nimmer een tegenstander van gouverneur Mauricius was geweest, dezen integendeel dank verschuldigd was, opgenomen in den kring van de ontevredenen, die jaren lang een stelselmatige campagne tegen hem hebben gevoerd, opgezet door het raadslid Salomon Du Plessis, een rijk en machtig plantage-eigenaar, raad van Politie, die met de rijke weduwe Pichot 
was gehuwd. Deze had een kring van familieleden en vrienden om zich verzameld, die den gouverneur niet alleen jaren lang het leven zuur hebben gemaakt, maar op de meest grievende wijze hem hebben gehoond en beleedigd. Zoowel de mannen als hun vrouwen behoorden tot die tegenpartij, door Mauricius als de "Cabale" betiteld. Dahlbergs aanstaande echtgenoote was een der hevigste cabalisten, tot welke o.a. behoorden met Du Plessis de commandeurs Chambrier en L'Archer van Keenenburg, de fiscaal Mr. J. S. Van Halewyn van Werven ${ }^{1}$ ), de raden van Politie Nicolaas Freher, Jean David Celliers, Dirk Guldensteeden, mr. Samuel Paulus Pichot, Johannes Moll, Isaac Godefroy en Johan Godfried Sultz ${ }^{2}$ ), alsmede de raden van Civiele Justitie, Jan Pieterse Visser, Estienne Couderc, Jean Paul Taunay, de secretaris van het Hof Ephraïm Comans Scherpingh en de beruchte Elisabeth van der Lith met haar laatste en vijfde echtgenoote, de Waalsche predikant ds. Duvoisin. Zij was reeds gehuwd geweest met de gouverneurs H. Temming, C. H. E. de Cheusses, en Joan Raye van Breukelerwaard en met den Waalschen predikant A. Audra. Haar invloed was groot en deze door den gouverneur genoemde ,,vetula beata" of ",'t salig oudwijf" stookte op onbarmhartige wijze de ontevredenen op.

Velen dezer "Cabale" waren aan elkaar verwant en om een indruk dezer familiekliek te geven vermelden wij hun familieband.

Mr. S. P. Pichot, N. Freher en J. P. Taunay waren zwagers, met de zusters l'Espinasse gehuwd. Visser was de stief-schoonvader van Guldensteeden, Brouwer was de schoonzoon van Moll, Pichot en Celliers waren zwagers van Du Plessis, Couderc was de schoonzoon van mevrouw Duvoisin. Celliers was op clandestiene wijze door ds Duvoisin met Constantia Maria Pichot in den echt verbonden. Comans Scherpingh was met de weduwe Van der Beets gehuwd, en de stiefdochter van Scherping, juffrouw Van der Beets, was met Jan Willem Pichot gehuwd, een neef van S. P. Pichot, stiefzoon van Du Plessis, enz.

Om een of andere reden had Dahlberg van den commandeur op 14 September 1750, huisarrest gekregen, waaruit hij eerst op 23 December werd ontslagen. Nu hij niet kon uitgaan, ontving hij geregeld bezoeken van de vrouwelijke leden der "Cabale”,

1) De familie van Halewijn van de Werve in Suriname, door Fred. Oudschans Dentz, W.I. Gids Maart 1932.

2) Was chirurgijn, 25 Nov. 1728 in Suriname aangekomen 
hetgeen Mauricius aanleiding gaf op 1 October 1750 in zijn journaal aan te teekenen.

„Dahlberg braveert op een ondragelijke wijze. De dames der "Cabale" met Mevrouw Duvoisin aan 't hoofd, de vrouw en dochter van Scherping etc. gaan hem dagelijx besoeken, en hij geeft se musijk. N.B. hij is verloofd aan de wed. van den capitein Brouwer, een der impertinenste helleveegen der cabale. $\mathrm{Zij}_{\mathrm{ij}}$ heeft een stuivertje, en een man, die nog zo onlangs hier gekoomen is als corporaal, met een zielenkooperstransport, en nu zo schielijk hoog geklommen is, meent dat dit een Cresus rijkdom zal zijn. Al zijn bravade is, om te behagen aan zijn infante. Men remarqueert hier weder de ondankbaarheid van dit land. Dahlberg is alles, wat hij aan mij schuldig is, vergeeten".

Twee dagen later, 3 October, was het dochtertje van Dahlbergs verloofde, mevrouw Brouwer, jarig. Hoe dit feest gevierd werd, zal uit het volgende blijken. In de eerste plaats teekent de gouverneur in zijn journaal op dien dag aan:

„De meeste scheepen vlaggen en schieten, even en meer of 't voor den Prins was. Het dochtertje van de wed. Brouwer word heeden vijf jaaren oud, daar zal 't avond een bal zijn'.

Dahlberg kon dit festijn helaas niet bijwonen, want ofschoon hij aan den gouverneur een request indiende om dien dag van huisarrest te worden ontslagen, werd er afwijzend op beschikt. Het bal had plaats, niet in haar eigen huis maar in dat van haar tante, de weduwe Wossink, die het groote huis op den hoek van het Gouvernementsplein bewoonde, de tegenwoordige Gouvernements-secretarie.

Hoe de aanstaande mevrouw Dahlberg met haar cabalistengasten zich dien avond heeft gedragen, heeft Mauricius aan directeuren der Societeit in zijn brief van 3 October 1750 no. 1197 medegedeeld.

Als een staaltje van de toenmaals in Suriname heerschende toestanden en van het gebrek aan eerbied voor den landvoogd Mauricius en van de praktijken van de cabalisten, geven wij dien brief in zijn geheel weer. De gouverneur schreef dan als volgt $\left.{ }^{1}\right)$ :

„De hoogbedroefde Weduwe van den Capitein Brouwer, die haar verongelukten Mans dood met heete tranen beschreid, kreeg in haar hoofd om op Saturdag den 3 October 1750 een eclatant Bal te geven, tot celebratie van de Geboortedag van

1) Recueil van Egte stukken en bewijzen, door Salomon du Plessis, enz. tegen Mr. Jan Jacob Mauricius, enz. Deel IV, stuk no. 54, blz. 295. 
haar Dochtertje, 't welk vijf jaren oud was. Om zulks met te meer eclat en bravade te doen, verzoekt zij daar toe het Huis van de Weduwe Wossink, haar Tante, een eenvoudige vrouw, die op haar Plantage is, en dus haar zonder erg dit heeft toegestaan. Dit huis NB staat op het Plein, vlak over dat van den Heer Commandeur, zoo dat' er de straat maar tusschen beide is, en vervolgens ook zoo digt bij 't Gouvernement, dat in de Gallery niet hard gesproken kan worden, of men kan 't op mijn stoep bescheidentlijk hooren.

De preparaties van dit Bal gaven aanstonds veel opspraak, dewijl 't juist den avond voor des Heeren $\mathrm{H}$. Avondmaal was. Ik weet, dat de Familie haar daar over remonstrantien heeft gedaan, gelijk ook de eigen Zwager Talbot, die genodigt was om 't Bal te openen, daar niet heeft willen gaan. Dus is ook desselfs Vrouw, Zuster van de Wed. Brouwer, t'huis gebleeven, en de eigen Moeder, de Wed. Bedlo, en haar andere Zuster, de Vrouw van Bley, zijn, zoo ras de musyk begon, na huis gegaan.

De Predikant Yver, welke 's anderdaags 't H. Nagtmaal zou uitdeelen, en ook 's namiddags de Dankzegging doen, hier van verwittigt zijnde, heeft door den Koster haar een beleefde waarschuwing laten doen, doch een fier antwoord gekreegen, dat het maar een Kinderbal zou zijn, zoo als best uit den Brief van zijn Eerw. zelfs gezien kan worden.

Om vijf uuren zag men over en ter zijde het Plein aankomen niet alleen alle de Kinderen der Cabale, maar ook een talrijk gezelschap van Heeren en Dames, vooral die van de Familie van Pichot en Scherping. Kort daar op hoorde men een geschal van Trompetten, en ten zes uuren begon het Bal, niet alleen van Kinderen, maar wel degelijk van groote menschen. Tegen zeven uuren wierp Leonard van der Beets, Voorzoon van Scherpings Vrouw, zwermers en raketten, zoo onbezuisd, dat ze tot op mijn stoep vloogen, en genoegzaam in 't huis van den Commandeurs, alles onder een groot gejouw van slaven; dit niet alleen, maar de twee Schildwagten, die voor mijn deur stonden en vooral die voor 't huis des Commandeurs, konden op hun post niet blijven door de zwermers, en als ze iets zeggen wilden, wierden ze uitgescholden en met oranjeappelen gegooid.

Omtrent agt uuren, wanneer de Slaven niet meer mogen op straat zijn, zonder een Lantaarn, stilde dit een weinig, en ik dagt dat het daar mede zou uit zijn. Doch na negenen, en dus na besloten Wagt, begon men weder op nieuw raketten en zwermers te werpen, 't welk ik door den Schout liet verbieden, gelijk men 
ook ophield. Doch kort daar op liet men weder met de Trompetten helder opblazen, en NB een der Trompetters was een der Militairen, die na negenen uit hun quartier niet mogen zijn, op poene van spitsroeden. Verder continueerde men met musyk en dansen. Ik ordonneerde daar op mijn Adjudant om den gem. Militair in arrest te laten brengen; waar op een Onder-Officier aan 't huis gekomen zijnde, en na den Militair met beleefdheid vragende, is hem de deur voor de neus geslooten, en men heeft den Militair laten eschappeeren.

Ik zond te gelijk den Schout, met order om de Musikanten te verbieden om verder te speelen, alzoo 't morgen Nagtmaal was, en de Wed. Brouwer hem binnen geroepen, en de reden gevraagt hebbende, waarom hij de Muzikanten zulks verbood, heeft hij nogmaals geantwoord, om dat het morgen Nagtmaal was. Waar op zij zeide: de Gouverneur is meester in zijn huis, en ik in ' $t$ mijne, en ik zal laten speelen. Egter de Musikanten daar op zig geretireert hebbende, heeft de Vrouw van den Secretaris Scherping tegen haar Zoon Leonard van der Beets gezegt: Leentje neem jij de Viool je kunt hem ook speelen, ze konnen het $u$ niet beletten: gelijk die dan ook beneffens Crepy, een Clercq ter Secretary, en zekeren Sielander, voortgevaren zijn met speelen, en 't gezelschap met dansen. Dit is nog 't minste. Maar bijna tusschen elken dans heeft Crepy en eenige andere uitgeschreeuwt: morgen zullen de Burgers blacke breddie eeten, Hoezee! waar op dan al de Kinderen, zoo hard zij konden dit Hoezee of Houree moesten naschreeuwen. Tussen beide had Leonard van der Beets de brutaliteit nog, van op de Trompet te blazen, niet ordentelijk, maar met het aller infaamste geluid des waerelds, terwijl de Wijven, Kinderen en Slaven overluid lachten en jouwden.

Dit heeft zoo geduurt tot half twaalf, met geduurige reprises van Hourees en spottelijk geblaas, waarop ik zond na den Heer Talbot, als de eenige Raadsheer van Politie, die aan 't Fort present was (terwijl alle de andere absent waaren) hem verzoekende aan 't Gouvernement te komen, om deeze historie zelf te zien en te hooren; hij kwam ook; en schoon het zijn Schoonzuster was, disapprobeerde hij haar doen ten hoogste. Deeze Conferentie met een Raadsheer zoo laat in den nacht, schijnt het gezelschap bedenken gegeeven te hebben, dat ik iets in den zin had, waar over ik eerst met een Raadsheer spreken wilde. Immers ten twaalf uuren ging het gezelschap na huis". 
In de ,Remarques op 't Relaas van 't Bal der Wed. Brouwer, 3 Octob. 1750" teekent Mauricius onder punt 1 aan ${ }^{1}$ ):

„De Remarques die op dit Relaas vallen, springen van zelfs in de oogen; doch om ' er een regt begrip van te hebben, moet men zig figureeren de situatie der plaats en de nabijheid van 't huis, daar al dit onlijdelijk geraas van Hourees, en trompetten gemaakt is. De bravade der Wed. Brouwer is te tastelijker, om dat anders haar eigen huis groot genoeg was tot een Kinderbal. En de intentie van bravade is te waarschijnlijker, om dat deeze Amante gepiqueert is over 't arrest van haar beminde Dahlberg".

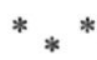

Niet lang na dit voorval, op 13 Maart 1751 trad Dahlberg met de weduwe Brouwer in het huwelijk. Hij was toen nog in militairen dienst. Volgens de huwelijksacte werd zij bijgestaan door haar moeder Johanna Maria Lemmers, weduwe Bedloo.

De sous-luitenant Dahlberg was thans door zijn echtgenoote mede-eigenaar van twee plantages geworden, nl. „Brouwershaven” aan de Perica en ,Carlsburg” aan de Boven Cottica. Toen hij het jaar daarna, 3 Maart 1752, ontslag uit den militairen dienst nam, wijdde hij zich verder aan zijn plantage-aangelegenheden. Bovendien had hij een huis in de Heerenstraat te Paramaribo gehuurd, waarvoor hij de voor dien tijd belangrijke som van 1000 gulden huur betaalde. Hij was thans op weg naar meer welvaart, rust en onafhankelijkheid.

Zelfs werd de gewezen korporaal tot raad van Politie en Crimineele Justitie verkozen, waarvoor hij op 19 November 1753 den eed aflegde, maar lang is Dahlberg geen raadslid geweest. Hij kon zich de weelde veroorloven een reis naar zijn geboorteland te maken en nam als raadslid op 5 Februari 1754 ontslag.

Met „,De Vrouw Elisabeth”, kapitein Jan Pons, vertrok hij 20 April naar Europa, bezocht Zweden en keerde het volgend jaar met hetzelfde schip terug. Op 20 April 1755 was hij weer in Paramaribo bij zijn gezin. Hij had ditmaal de reis alleen gedaan.

Een tweede maal vertrok Dahlberg op 25 April 1761 met het schip , Jean François" naar Zweden met vrouw en twee kinderen. Ditmaal bleef hij langer weg, want eerst 20 Maart 1765 keerde hij met het schip „De Spion”, kapitein Kersjes Prent in Suriname terug met zijn in Stockholm op 5 December 1763 geboren dochtertje Carolina Wilhelmina.

1) Ibidem, blz. 297. 
Dahlberg heeft dé reis naar Zweden nog aan een zakelijk en wetenschappelijk doel dienstbaar gemaakt. Hij had nl. een tros bloemen, enkele vruchten en bladeren van het quassiehout op brandewijn medegenomen. Deze plant was - zooals tevoren medegedeeld - als koortswerend middel in gebruik gekomen en sedert 1730 het eerst door den neger Quassie toegepast, aan wien zij den naam ontleende. Dahlberg wenschte de aandacht van Linnaeus hierop te vestigen $\left.{ }^{1}\right)$. Hij had daarmede niet alleen een menschlievend maar tevens een zakelijk oogmerk. Op 28 Mei 1763 promoveerde te Upsala Carolus M. Blom uit Smoland, die uit een koninklijke beurs studeerde, op het proefschrift ${ }^{2}$ ) De Ligno arboris quassiae ${ }^{3}$ ), in welk proefschrift de volgende Nederlandsche brief is opgenomen:

„Dat 27 Nov.

Rec. 12 Dec. 1764.

Hoog-Edele Gestrenge Heer,

Heeden in het politicq weinig of niets te verhandelen zijnde, alsoo de saak, waarvan ik onder den 20 deeser de eer had mentie te maaken, nog niet afgedaan is neem ik de vrijheid door deese, een dissertatie van het quassie hout over te senden, welke hier door desselfs heilsaame nuttigheid bij de botanisten seer in agting gekoomen is; wijlen den Heer Van Marteville heeft veel baat voor sijne quijnende siekte aan het selve gevonden; den Heer Legations-Secretaris Titzchkau, welke seedert dertig jaaren hier van weegens het Saxische Hof resideert, is een leevendig Getuige dat gemelde hout seer nuttig voor het menschelijk ligchaam is, alsoo hij tweewerf desselfs herstelling enkelijk aan de geneeslijke kragt van dit hulpmiddel is verschuldigt geweest, het welk thans hier in naam begint te raaken; en vermits het van de Colonie Suriname, onder het ressort van Haar Mogende, sijn oorsprong neemt, agte ik het van mijne pligt te zijn, daarvan kennis te moeten geeven, nadien het even soo wel als de Cortex Peruviani of China en de Radix Rhabarbar met de tijd eene wigtige handeltak soude kunnen worden, welke ik tot mijn leedweesen bespeure dat de Sweeden sig tragten toe te eigenen ver-

1) Linnaeus gaf het den naam Quassia amarum L.

2) Koloniale Boekerij te Paramaribo, $\mathrm{H}$ 89, waar in de catalogus bij vergissing staat Ligne, inplaats van Ligno.

3) De Nederlandsche vertaling van dit proefschrift luidt: Het Quassiehout uit Suriname als voornaam koortsmiddel. 
mits sij op dezelve geen het minste regt hebben; seekeren Dahlberg, Oud-crimineel Raad der Policie en Justitie te Suriname, een Sweed van geboorte, aan wien het (soo hij voorgeeft) maar alleenlijk bekend is in Suriname, waar dit hout wascht, heeft hier met seeker botanist van de kroon een monopolium opgeregt, om het teegens twee ducaten het pond te verkoopen: De menschlievendheid vereischt dat gemelde geneesmiddel voor desselfs heilsaamheid en deugdelijke werking meerder in Europa verspreid werd; waartoe de Nederlandsche geoctroyeerde Westindische Compagnie misschien aanleiding geeven kan; tot meerder seerkerheid voege ik hier neevens een stukje van het hout in, het welk van de bastzijde genoomen is, ook heb ik eene afteekening van het blad en vrugt aan het einde van gemelde dissertatie doen voegen, tot nader opheldering, in hoope dat haar Hoog Mog. mijne diesweegens aangewende vlijt sullen gelieven te approbeeren den opgenoemden Heer Titzchkau heeft mij versprooken diesweegens eene dissertaatie te geeven, welke hij beesig is met op te stellen, dog alsoo ik bevreest ben dat een langer versuim misschien nadeelig voor de Nederlandsche handeltak soude kunnen zijn, heb ik niet langer op deselve kunnen wagten.

Waar meede, \& Stokholm den 27 November 1764,

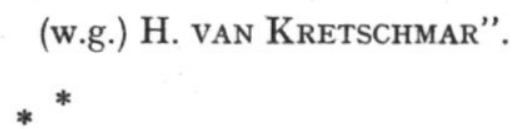

Dahlberg richtte in Zweden op 16 December 1762 een verzoekschrift tot den koning om dien te verzoeken zijn invloed aan te wenden bij hunne Hoog Mogenden om de belasting van $\mathrm{f}$ 600.-, welke de Luthersche gemeente te Paramaribo jaarlijks aan het Militair Hospitaal moest betalen, kwijt te schelden. De pogingen daartoe in Suriname aangewend, hadden tot dusverre steeds gefaald. Of 's konings invloed succes heeft gehad, is niet bekend, maar wel weten wij, dat in 1789 werd toegestaan deze belasting met een som van $f 8.000$,- af te koopen. De oud-ouderling der Evangelisch Luthersche gemeente J. G. Felbinger bood deze som op 4 Februari 1768 aan, welk aanbod dankbaar werd aanvaard. Het consistorie te Amsterdam wendde zich daarop met ondersteuning van den gouverneur tot de directeuren der Societeit, die daarop 5 October 1789 antwoordden. Het volgend jaar kreeg de zaak haar beslag.

De directeuren deden den gouverneur de vraag, waarom 
Dahlberg weder naar Suriname vertrok, waarop deze den 18den Januari 1766 antwoordde:

„En Dahlberg aangaande kan ik niet anders begrijpen, hij hier is gekoome om sijn finantiën te herstellen, die seer gedelabreert benne door de depenses, die hij in Sweeden heeft gedaan, en houd sig ook seer stil op sijn plantage, ook kan niet merke dat hij eenig werk maakt van het quassy houd egter hebben de fiscaal Texier gelast om het oog op sijn conduits te houden, en onder de hand daarmee te informeeren, conform d'orders van U Edele Groot Achtbaare.

En ten opsigte uitgaande rechten op het quassie houd sal dan over een comparitie belegge met den ontfanger Lynslager en boekhouder-generaal".

Nog eenmaal, en voor het laatst, ging Dahlberg naar zijn geboorteland terug, toen hij 11 November 1771 ten derden male de reis met zijn echtgenoote aanvaardde met het schip „De Swaen” kapitein Govert Theunis. Zij keerden eerst 9 Juli 1775 per ,,Maria Reinbrandina Agnes", kapitein J. F. Gnette, te Paramaribo terug.

Niet lang daarna zien wij in de Wekelijksche Surinaamsche Courant van 25 October 1775 no. 64 gewag gemaakt van de advertentie van Dahlberg, waarin hij met bewijzen staaft, dat de praatjes, welke sedert eenige jaren in omloop waren, gelogen waren, nl. dat hij den vrijen neger Baron, aanvoerder der Marrons, aan een Jood had verkocht en zijn belofte niet was nagekomen, hem, na zijn reis naar Zweden, waarheen deze hem zou hebben vergezeld, de vrijheid te geven, ingevolge waarvan Baron een der meest gevreesde wegloopers werd. Wij hebben in De W.I. Gids daarover volledige inlichtingen medegedeeld ${ }^{1}$ ). Het hof van Politie en Crimineele Justitie heeft daarop Dahlberg volkomen recht laten wedervaren.

Dahlberg was, zooals wij schreven, tot grooten welstand gekomen. Toen Stedman, de bekende schrijver van ,Narrative of a five years' expedition against the revolted Negroes of Surinam", Dahlberg na zijn derde reis in Suriname bezocht, toonde deze hem een gouden snuifdoos met brillanten ter waarde van $£ 600$ afgezet en verder 2 in goud gevatte muntstukjes, waarop de volgende inscriptie voorkwam: ,,Soli Deo Gloria. Fortuna beati-

1) Het einde van de legende Dahlberg-Baron, door Fred. Oudschans Dentz, De W.I. G. Juli/Aug. 1928. 
cum etc." Deze 2 muntstukjes vertegenwoordigden al het geld dat Dahlberg bezat, toen hij in Suriname kwam!

Hierop vroeg Stedman: „Hebt gij gewerkt?” „Neen” was het antwoord. „Hebt gij gebedeld”? „Neen” was nogmaals Dahlbergs antwoord. „Gij hebt niet gestolen”? was de derde vraag. Wederom luidde het antwoord ontkennend, maar Dahlberg voegde er aan toe: ,,entre nous, ik klaagde en speelde de belangstellende, wat soms zeer noodzakelijk is, en ik verkieslijker vond dan werken, bedelen en stelen".

Zonder werken, stelen of bedelen was de Zweedsche korporaal in Suriname rijk geworden, waar hij 6 September 1781 overleed en den volgenden dag in den Nieuwen Oranjetuin werd begraven.

Zijn in Zweden geboren dochtertje, Carolina Wilhelmina, was slechts zeven jaar oud, toen zij op 9 November 1770 te Paramaribo was overleden, en zijn echtgenoote, de woelzieke tegenstandster van Mauricius en eenmaal lid van de beruchte "Cabale" volgde hem 29 Juli 1803.

Eenige jaren geleden woonden er in Suriname nog enkele kleurlingen met den naam Dahlberg, die misschien van den Zweedschen Dahlberg afstammen. Zekerheid bestaat daarover niet.

Als bijzonderheid kan nog worden medegedeeld, dat Linnaeus ter eere van Dahlberg een geslacht der Leguminose „Dahlbergia” heeft genoemd. Uit het artikel van dr. J. Lanjouw en dr. H. Uittien blijkt, dat Dahlberg zich zeer verdienstelijk heeft gemakkt voor bekendmaking der Surinaamsche geneeskruiden, behalve het quassiehout, waarvan zijn manuscript, handelend over een verzameling planten, welke hij naar Europa zond, getuigt. Dit manuscript is aanwezig in het Natural History Museum te Londen en een afschrift ervan in de boekerij van het Botanisch Museum en Herbarium te Utrecht.

Lit terat u u :

Surinaamsche archivalia.

J. G. Stedman, Narrative of a five years' expedition against the Revolted Negroes of Surinam, 1813.

West-Indië deel II, 1858.

C. A. van Sypesteyn, Mr. J. J. Mauricius, 1858.

J. Wolbers, Geschiedenis van Suriname, 1861.

Pharmaceutisch Weekblad, 1911 en 1916.

Dr. J. Lanjouw en dr. H. Uittien, Surinaamsche geneeskruiden in de tijd van Linnaeus, De W.I.G. 1934/5, blz. 173 e.v. 